\title{
PERCEPÇÃO DOS ESTUDANTES SOBRE DISCIPLINAS DO CURSO DE FARMÁCIA QUE USAM METODOLOGIAS ATIVAS E TECNOLOGIAS DE INFORMAÇÃO E COMUNICAÇÃO
}

\section{STUDENT PERCEPTION ABOUT PHARMACY COURSE DISCIPLINES THAT USE ACTIVE METHODOLOGIES AND INFORMATION AND COMMUNICATION} TECHNOLOGIES

\author{
Júlio Cézar Borella ${ }^{1}$; Monica Maruno루 César Augusto Sangaletti Terçariol' ${ }^{1}$; Josinete \\ Salvador Alves ${ }^{1}$
}

1 - Centro Universitário Barão de Mauá, Curso de Farmácia, Ribeirão Preto, São Paulo, Brasil.

\section{RESUMO:}

Atualmente, Metodologias Ativas e Tecnologias de Informação e Comunicação estão sendo utilizadas como instrumento nos processos de ensino e aprendizagem. Neste sentido, este trabalho visou avaliar a percepção dos estudantes que passaram pela experiência de atuarem em disciplinas (Projetos Farmacêuticos) que utilizam estes recursos. Trata-se de uma pesquisa de caráter exploratório descritivo, com abordagem quali-quantitativa e foi realizada a partir de uma amostra de estudantes $(n=35)$, por meio de questionário. As avaliações qualitativas foram realizadas por pesquisa fenomenológica envolvendo análise temática e os dados quantitativos foram analisados em programa SPSS. Os resultados mostraram que maioria dos estudantes era do sexo feminino, trabalhadora e oriunda de escolas públicas $(74 \%)$. Com relação à melhor forma que eles creem que os conteúdos deveriam ser desenvolvidos, $47 \%$ acredita que os professores deveriam estimular os estudantes a "pensar" sobre os temas e que estes conteúdos deveriam ser ministrados associando metodologias ativas, com outras metodologias (89\%) e não somente utilizando metodologias ativas (0\%). A respeito das disciplinas Projetos Farmacêuticos, $71 \%$ dos estudantes concordaram que elas facilitaram o aprendizado e foram de média importância para sua formação profissional (54\%). Eles acharam interessante a proposta (76-94\%), o desenvolvimento (58-79\%), o tipo de avaliação (68-77\%) das disciplinas e, ótimo ou bom (>90\%), o papel do professor tutor. Deste modo, apesar da boa aceitação observada, é importante, na percepção dos estudantes, mesclar as metodologias de ensino e aprendizagem no desenvolvimento das disciplinas.

Palavras chaves: Metodologias ativas. Tecnologia na educação. Educação em farmácia.

\section{ABSTRACT:}

Currently, Active Methodologies and Information and Communication Technologies are being used as an instrument in the teaching and learning processes. In this sense, this work aimed to evaluate the perception of students who had the experience of working in disciplines (Pharmaceutical Projects) that use these resources. This is a descriptive exploratory study, with a qualitative and quantitative approach and was carried out from a sample of students $(n=35)$, using a questionnaire. Qualitative assessments were carried out through phenomenological research involving thematic analysis and quantitative data were analyzed using the SPSS program. The results showed that the majority of students 
were female, working and coming from public schools (74\%). Regarding the best way that they believe that content should be developed, $47 \%$ believe that teachers should encourage students "to think" about topics and that these contents should be taught by associating active methodologies with other methodologies (89\%) and not only using active methodologies (0\%). Regarding the Pharmaceutical Projects disciplines, $71 \%$ of the students agreed that they facilitated learning and were of medium importance for their professional training (54\%). They found the proposal (76-94\%) interesting, the development $(58-79 \%)$, the type of assessment (68-77\%) of the subjects and, excellent or good (>90\%), the role of the tutor teacher. Thus, despite the good acceptance observed, it is important, in the students' perception, to merge teaching-learning methodologies in the development of subjects.

Key words: Active teaching-learning methodologies. Technology in education. Education in pharmacy.

\section{INTRODUÇÃO}

$\mathrm{Na}$ atualidade, uma das principais finalidades dos centros de formação profissional é formar profissionais que estejam aptos para desempenhar seu papel na sociedade, com ética e competência. Isto parece óbvio, mas nas últimas décadas, com o acelerado desenvolvimento científico-tecnológico, percebeu-se que houve um movimento de distanciamento daquilo que se ensina nas escolas, com a capacitação que a sociedade deseja para estes profissionais (CASTRO et al., 2019). Este parece ser um dos fatores que faz com que haja aumento no índice de desemprego no Brasil, propiciado, não por falta da colocação, mas por falta de profissional capacitado para desempenho da função (CINTRA, 2019).

Esta situação social pode ser percebida na área farmacêutica, quando se analisa as novas diretrizes curriculares para formação deste profissional. Fica evidente que 0 profissional desejado pela sociedade é aquele que tenha desenvolvido durante sua graduação, conhecimento, habilidades, competências e atitudes essenciais para sua atuação (CHAGAS et al., 2019).

No caso das Ciências Farmacêuticas, estas competências foram alicerçadas em três eixos que envolvem: I. Cuidado em saúde; II. Tecnologia e inovação em saúde e III. Gestão em saúde. Todos eles devem ser desenvolvidos na totalidade das disciplinas, desde o primeiro semestre de estudos, com abrangência interdisciplinar e transversal dos conteúdos (SOUSA; BASTOS, 2016; BRASIL, 2017).

Sendo assim, com esta realidade instaurada, pressupõe-se que novas ações devam ser desenvolvidas pelas instituições de ensino, no sentido de alcançar estes objetivos e colocar profissionais capacitados para desempenhar suas funções, tanto no setor privado, como no setor público (LIMBERGER, 2013). 
Por outro lado, principalmente em instituições particulares, o perfil da maioria dos ingressantes do curso de farmácia é de trabalhadores assalariados que entraram nesta condição de forma precoce e possuem dificuldades para os estudos e falta de tempo para a realização de estágios.

Atualmente, este público é formado predominantemente pela geração $Y$, que se caracteriza por pessoas agitadas, ansiosas, impacientes, empreendedores, independentes e que possuem habilidades para lidar com as novas tecnologias (nativos digitais), apreciam os desafios, atuam em múltiplas tarefas ao mesmo tempo e são capazes de receber informações múltiplas, que resultam em correlações desordenadas e fragmentadas.

Estes jovens estão conectados com a realidade por meio da internet e representam um desafio para os docentes, quanto à utilização de metodologias de ensino aprendizagem mais eficazes (ALVES et al., 2019).

Também é de consenso que o processo de ensino aprendizagem pode ser potencializado quando são dadas condições aos estudantes de eles próprios observarem a realidade e os problemas derivados dela e a partir daí desenvolver soluções para a melhoria destas condições (FARIAS et al., 2015).

Ao mesmo tempo, a utilização das tecnologias de informação e comunicação (TICs), com uso do computador e da internet, por exemplo, poder ser um instrumento de construção do conhecimento, motivando o desenvolvimento de habilidades e no auxílio para pesquisa e atualização de conhecimento (VENDRUSCOLO et al., 2013).

Alguns tipos de metodologias ativas se prestam muito bem para estes mesmos objetivos, se forem convenientemente concebidas e realizadas. Uma delas, a Aprendizagem Baseada em Projetos, tem por característica ser centrada no estudante, proporcionando um ambiente propício ao desenvolvimento da capacidade para construir ativamente a própria aprendizagem, por meio de um processo de investigação estruturada em torno de um projeto. Há possibilidade de desenvolver e utilizar o raciocínio crítico e as habilidades de comunicação para a resolução dos problemas, pois há necessidade do trabalho em grupo e de ensinar o que aprendeu. Diferencia-se, portanto, do ensino tradicional, no qual o ensinar é simplesmente uma transmissão de informações (FARIAS et al., 2015).

A literatura aponta que a associação de metodologias ativas de aprendizagem com as novas tecnologias de informação e comunicação são extremamente eficazes para despertar a motivação discente e promover a construção do conhecimento (VENDRUSCOLO et al., 2013). 
Deste modo, para possibilitar a formação profissional almejada pela sociedade, uma das alternativas encontradas para curso de Farmácia foi introduzir na grade curricular disciplinas com abrangência interdisciplinar e transversal dos conteúdos, usando metodologias ativas e que propiciem o desenvolvimento de habilidades, competências e atitudes inerentes do farmacêutico, de modo ativo e utilizando as tecnologias de informação e comunicação para o contato com estas realidades para solucionar os problemas e desenvolver projetos que impactem positivamente a comunidade.

Pensando nesta situação, foram propostas as disciplinas de Projetos Farmacêuticos I, II e III, para serem introduzidas na grade curricular do curso.

Projetos Farmacêuticos I, que ocorre no 70 semestre, tem a finalidade de desenvolver ações de extensão junto à comunidade para que a população tome conhecimento e faça uso das Práticas Integrativas e Complementares de Saúde (NASCIMENTO et al., 2018), principalmente Fitoterapia, Homeopatia e Acupuntura, disponibilizadas no Sistema Único de Saúde.

Projetos Farmacêuticos II, realizado no 80 semestre, tem como tema os modelos de estudo saúde e doença, trabalhando inúmeros assuntos de importância e interesse para o farmacêutico, como por exemplo, uso e descarte de medicamentos, uso correto de medicamentos, interações medicamentosas e alimentares, entre outras. Este processo sempre culmina com o desenvolvimento de alguma pesquisa e/ou ação na comunidade com o objetivo de esclarecimento sobre o tema proposto.

Projetos Farmacêuticos III, desenvolvido no 90 semestre, tem como finalidade o desenvolvimento de um processo, ou produto farmacêutico, ou cosmético, onde o estudante se envolve com as etapas essenciais do trabalho na farmácia de manipulação ou indústria farmacêutica (pesquisa \& desenvolvimento, produção, apresentação do produto, mercadologia e promoção).

As disciplinas de Projetos Farmacêuticos I, II são desenvolvidas em três etapas. A primeira, com auxílio do professor tutor, onde se deseja o trabalho em grupo dos estudantes, tem como objetivo o contato com o tema e a realidade dos problemas que 0 envolvem. A segunda etapa, os estudantes se envolvem com o desenvolvimento teóricoprático do projeto de extensão ou pesquisa que será realizado. Há produção de materiais que serão utilizados nestas intervenções, como por exemplo, folders, painéis, vídeos, realização de pesquisas de campo, etc. Na terceira etapa, o projeto é concretizado, sendo realizado no espaço programado e/ou apresentado em eventos científicos (ALVES et al., 2019). 
Projetos Farmacêuticos III difere dos outros na terceira fase, pois os grupos apresentam os produtos desenvolvidos e manipulados na segunda etapa (medicamentos, cosméticos e afins) para uma banca formada por docentes farmacêuticos.

As avaliações das disciplinas são realizadas após a finalização da primeira etapa (contato e avaliação dos problemas que envolvem o tema), por meio de atividades onde os estudantes devem mostrar seu entendimento em relação à proposta da disciplina, e a segunda, com a apresentação formal ou realização do projeto.

Para concretização destes projetos são necessárias atividades de preparo que envolve extensa pesquisa sobre o tema, em várias fontes de informação, culminando com a produção de material impresso (folders e painéis), audiovisual (filmes) e produto (medicamentos e cosméticos).

Desta forma, o desenvolvimento destas disciplinas está alicerçado no trabalho de pesquisa dos estudantes sobre o tema, com o uso de metodologias ativas (Aprendizagem Baseada em Projetos), no qual são planejadas e realizadas ações ou desenvolvidos e manipulados produtos que deverão envolver ou favorecer a comunidade. Para isto, novas tecnologias de informação e comunicação devem ser utilizadas para alcançar os objetivos.

A pesquisa em educação e saúde trabalha com os significados das ações, motivações, aspirações, crenças, valores, atitudes, apreendidos a partir do olhar do pesquisador que capta parte da realidade. Deste modo, o interesse maior deste trabalho foi analisar a percepção dos estudantes, entendendo-o como resultante da dinâmica das relações sociais, ou seja, das vivências e experiências do cotidiano, inclusive com a instituição de ensino (MINAYO, 2003).

Após implantação das disciplinas de Projetos Farmacêuticos na grade curricular do curso de Farmácia, algumas turmas passaram pela experiência de participar e se envolver com as atividades propostas. Sendo assim, houve o questionamento se seriam estas experiências de ensino realmente efetivas, em relação à aprendizagem e no seu desenvolvimento como futuro profissional.

Neste sentido, o objetivo deste trabalho foi avaliar a percepção que possuem os estudantes que frequentaram as disciplinas de Projetos Farmacêuticos, avaliando no aspecto educacional e na função de desenvolvimento de habilidades, competências e atitudes para as atividades profissionais. De forma mais detalhada, a perspectiva também foi avaliar a percepção do estudante, quanto ao aspecto educacional inovador, referente ao tipo de aprendizagem desenvolvido nas disciplinas e a percepção do acadêmico quanto ao 
conteúdo e atividades desenvolvidas, verificando o seu reconhecimento, levando em consideração a sua formação profissional.

\section{METODOLOGIA}

O estudo compõe-se de uma pesquisa de campo descritiva que visou observar, descrever e documentar aspectos de uma situação que ocorreu, trazendo também uma abordagem quantitativa associada a aspectos qualitativos (fenomenologia), os quais se fundamentam no conhecimento como processo em produção dinâmica possível a partir da experiência humana (POLIT; HUNGLER, 1995).

A abordagem qualitativa é adequada aos objetivos desta investigação à medida que o processo de ensino-aprendizagem perpassa por processos sociais, intermediados pela objetividade e subjetividade, capazes de incorporar as questões de significado e intencionalidade como inerente aos atos, às relações e às estruturas sociais (MINAYO, 2003; FONTELLES et al., 2009).

Foram utilizados aportes teóricos e metodológicos pertinentes ao objeto de estudo, entre eles as Diretrizes Curriculares Nacionais do Curso de Graduação em Farmácia, publicada em 20 de outubro de 2017 (BRASIL, 2017), que define, em âmbito nacional, os princípios, fundamentos, condições e procedimentos da formação de farmacêuticos.

Também foi considerada a Portaria INEP no 291, de 8 de junho de 2016, que trata do Exame Nacional de Desempenho dos Estudantes (BRASIL, 2016). Esta portaria descreve as competências que o estudante de farmácia deve possuir para desenvolvimento de suas atribuições profissionais.

É importante ressaltar que, para a realização deste estudo, a privacidade e a individualidade da amostra estudada foi garantida de acordo com a Resolução n 466/2012 do Ministério da Saúde (BRASIL, 2012), que tem o mérito de dar ênfase aos compromissos éticos com os sujeitos da pesquisa, sejam eles indivíduos, seja a coletividade.

O material empírico da investigação, preparado para esta finalidade, foi um questionário aplicado aos estudantes que desejaram participar e que estivessem dentro do critério de inclusão para esta pesquisa. Tal critério foi estabelecido incluindo todos os estudantes que já teriam frequentado as três disciplinas de Projetos Farmacêuticos do curso de Farmácia do Centro Universitário Barão de Mauá. Não houve nenhum tipo de critério de exclusão. Desta forma, a partir de 112 estudantes que frequentam todos os 
períodos do curso de Farmácia, o número de participantes do estudo foi limitado, pois as turmas nas quais se desenvolveu este trabalho somavam 40 estudantes.

Os dados foram coletados no período de agosto a novembro de 2019 , sendo a amostra constituída por 35 estudantes. Este número de estudantes, que concordaram em participar da pesquisa, assinou o termo de consentimento livre e esclarecido.

O questionário, contendo questões de múltipla escolha e dissertativas, foi dividido em quatro seguimentos: o primeiro designa a origem do respondente; o segundo aborda quais seriam as mais adequadas formas de desenvolver os conteúdos programáticos; o terceiro está relacionado à percepção, de forma global, das disciplinas e o último seguimento foca especificidades para cada uma delas.

Com relação à análise qualitativa, na pesquisa fenomenológica (análise temática), a avaliação dos discursos dos entrevistados se estabelece a partir das convergências e repetições entre estes discursos. Neste caso, as narrativas descritas são examinadas pelo seu conteúdo em função de quesitos pré-estabelecidos (DRIESSNACK et al., 2007).

Sendo assim, os quesitos avaliados nos questionários respondidos pelos discentes foram:

I. Necessidade de uso das TICs para desenvolvimento dos conteúdos.

II. Importância das disciplinas na formação profissional.

Os depoimentos foram numerados e, após sucessivas leituras, foram separadas as unidades de significado, por meio da redução fenomenológica, o qual permite compreender o fenômeno estudado. A partir disso, algumas citações de significado foram apresentadas e discutidas.

Os dados obtidos da análise quantitativa foram codificados e digitados em planilha eletrônica, em forma de banco de dados EXCEL for Windows e analisados pelo programa "Statistical Package for the Social Science (SPSS)" versão 10.1 para Windows.

Conforme normas do Conselho Nacional da Saúde, por meio da Resolução nº 466, de 12 de dezembro de 2012, que regulamenta as pesquisas com seres humanos, o projeto foi encaminhado ao Comitê de Ética em Pesquisa com Seres Humanos (CEP) do Centro Universitário Barão de Mauá, para análise e emissão de parecer. A pesquisa foi aprovada e liberada em 7 de junho de 2019, com o CAAE: 09408918.8.0000.5378 e número do parecer: 3.378.259. 


\section{RESULTADOS}

Após aplicação tabulação e análise das respostas dos questionários foi possível obter melhor entendimento de como os estudantes avaliaram a experiência de frequentarem as disciplinas de Projetos Farmacêuticos.

\subsection{Caracterização dos graduandos que participaram da pesquisa}

Com relação à origem dos respondentes, 83\% (29) eram do sexo feminino e 17\% (6) do masculino. Todos eles (100\% - 35) trabalhavam no período que não estavam na escola. Suas idades ficaram no intervalo entre 21 a 43 anos, sendo que a média foi de 25 anos e $74 \%$ (21) deles concluíram o ensino médio em escolas públicas.

\subsection{Forma adequada para desenvolvimento dos conteúdos programáticos das disciplinas}

No segundo seguimento do questionário foram obtidas informações da percepção do estudante sobre como ele consideraria o método mais adequado de ensino aprendizagem para os conteúdos propostos nas disciplinas.

Uma das questões se referia ao comportamento ideal do professor frente ao objetivo de ensinar. A maior parte dos estudantes $(47 \%$ - 17) assinalou a alternativa que descrevia a ação dos professores persuadindo os educandos a "pensar" sobre o tema. $28 \%$ (10) gostariam que os professores já trouxessem os "assuntos prontos", 17\% (6) achariam melhor realizar leituras sobre o assunto e outros $3(8 \%)$ assinalaram que não se importariam como estes conteúdos seriam tratados pelos professores.

Em outro questionamento, ainda em relação quanto à forma que os conteúdos poderiam ser desenvolvidos nas aulas, nenhum dos respondentes $(0-0 \%)$ optou por desenvolvimento das disciplinas tendo somente metodologias ativas, $11 \%$ (4) desejariam as disciplinas sendo desenvolvidas por métodos tradicionais, somente com aulas expositivas. $89 \%$ (31) assinalaram que o ideal seria uma associação de metodologias ativas com outras metodologias de ensino.

\subsection{Percepção global das disciplinas}

$\mathrm{Na}$ terceira parte do questionário foram apresentadas questões que envolvem a 
visão geral do estudante em relação às disciplinas Projetos Farmacêuticos. As assertivas que estavam inclusas nas questões estão apresentadas na Tabela 1, juntamente com os resultados obtidos nesta sondagem.

Tabela 1. Percepção global das disciplinas Projetos Farmacêuticos

\begin{tabular}{l|c|c}
\hline \multicolumn{1}{c|}{ Assertivas } & Sim \% (n) & Não \% (n) \\
\hline $\begin{array}{l}\text { Para desenvolvimento dos conteúdos } \\
\text { relacionados aos projetos, houve necessidade } \\
\text { do uso de tecnologias de informação e } \\
\text { comunicação (TICs). }\end{array}$ & $100(35)$ & $0(0)$ \\
\hline $\begin{array}{l}\text { A metodologia de aprendizagem facilitou a } \\
\text { compreensão sobre o assunto abordado, no } \\
\text { sentido do estreitamento entre conhecimentos } \\
\text { teóricos e práticos. }\end{array}$ & $71(25)$ & $29(10)$ \\
\hline $\begin{array}{l}\text { Foram necessários conhecimentos prévios de } \\
\text { algumas disciplinas do curso para o } \\
\text { desenvolvimento dos projetos. }\end{array}$ & $77(27)$ & $23(8)$ \\
\hline $\begin{array}{l}\text { Os resultados obtidos nos projetos resultaram } \\
\text { em alguma vantagem ou benefício para a } \\
\text { população, seja ela leiga ou científica. }\end{array}$ & $60(21)$ & $40(14)$ \\
\hline
\end{tabular}

Fonte: elaborado pelos autores

Finalizando esta parte do questionário, a opinião em relação à importância que desempenharam as disciplinas de Projetos Farmacêuticos na formação profissional dos estudantes foi questionada. Como respostas, obtivemos 54\% (19) como média importância; 26\% (9) pequena importância; 14\% (5) nenhuma importância e 6\% (2) grande importância.

\subsection{Avaliação detalhada das disciplinas}

A última parte do questionário envolvia a avaliação de cada uma das disciplinas Projetos Farmacêuticos (I, II e III). Os resultados obtidos foram sumarizados na Tabela 2. 
Tabela 2. Avaliação detalhada das disciplinas Projetos Farmacêuticos (PF)

\begin{tabular}{|c|c|c|c|c|}
\hline Questão & Avaliação & $\begin{array}{l}\text { PF I } \\
\% \text { (n) }\end{array}$ & $\begin{array}{l}\text { PF II } \\
\% \text { (n) }\end{array}$ & $\begin{array}{l}\text { PF III } \\
\%(n)\end{array}$ \\
\hline $\begin{array}{l}\text { Proposta da } \\
\text { disciplina }\end{array}$ & $\begin{array}{c}\text { Desinteressante } \\
\text { Indiferente } \\
\text { Interessante }\end{array}$ & $\begin{array}{c}6(2) \\
18(6) \\
76(26)\end{array}$ & $\begin{array}{c}9(3) \\
15(5) \\
76(26)\end{array}$ & $\begin{array}{c}0(0) \\
6(2) \\
94(33)\end{array}$ \\
\hline $\begin{array}{l}\text { Desenvolvimento } \\
\text { da disciplina }\end{array}$ & $\begin{array}{c}\text { Desinteressante } \\
\text { Indiferente } \\
\text { Interessante }\end{array}$ & $\begin{array}{c}3(1) \\
39(13) \\
58(19)\end{array}$ & $\begin{array}{c}9(3) \\
21(7) \\
71(25)\end{array}$ & $\begin{array}{c}0(0) \\
21(7) \\
79(27)\end{array}$ \\
\hline $\begin{array}{l}\text { Processo de } \\
\text { avaliação da } \\
\text { disciplina }\end{array}$ & $\begin{array}{c}\text { Desinteressante } \\
\text { Indiferente } \\
\text { Interessante }\end{array}$ & $\begin{array}{c}3(1) \\
29(10) \\
68(23)\end{array}$ & $\begin{array}{c}6(2) \\
23(8) \\
71(25)\end{array}$ & $\begin{array}{c}6(2) \\
17(6) \\
77(27)\end{array}$ \\
\hline $\begin{array}{l}\text { Papel } \\
\text { desempenhado } \\
\text { pelo professor } \\
\text { tutor na disciplina }\end{array}$ & $\begin{array}{l}\text { Péssimo } \\
\text { Ruim } \\
\text { Regular } \\
\text { Bom } \\
\text { Ótimo }\end{array}$ & $\begin{array}{c}0(0) \\
0(0) \\
9(3) \\
59(20) \\
32(11)\end{array}$ & $\begin{array}{c}0(0) \\
3(1) \\
3(1) \\
71(25) \\
23(8)\end{array}$ & $\begin{array}{c}0(0) \\
6(2) \\
3(1) \\
50(18) \\
42(15)\end{array}$ \\
\hline
\end{tabular}

Fonte: elaborado pelos autores

\subsection{Análise temática das disciplinas}

$\mathrm{Na}$ coleta de dados verificaram-se convergências e repetições no discurso dos discentes em relação aos quesitos avaliados. As respostas, após sucessivas leituras, foram separadas em unidades de significado e a partir disto, algumas citações traduziram estas percepções dos estudantes.

Um dos quesitos estava relacionado à necessidade de uso das TICs para desenvolvimento dos conteúdos, projetos e avaliações das disciplinas. Neste aspecto, alguns estudantes comentaram: 
"Foi necessário o uso da internet para pesquisar os temas dos projetos, principalmente os artigos científicos". (Estudante 1).

"Usei para busca em base de dados para consulta de medicamentos, interações medicamentosas e outras informações relacionadas com as doenças". (Estudante 2).

"Pesquisa de dados, artigos e informações sobre algo de suma importância para acrescentar ao projeto". (Estudante 3).

Outro quesito avaliado foi a importância que estas disciplinas teriam na formação dos estudantes. Foi solicitado que, se houvesse alguma importância, descrevesse qual seria. Os depoimentos de alguns estudantes exemplificam os esclarecimentos a respeito deste questionamento:

"Os projetos nos ajudaram a amadurecer na vida acadêmica e a aprender a pesquisar". (Estudante 4).

"Houve o desenvolvimento do potencial científico e conhecimento aprofundado nas áreas específicas". (Estudante 5).

"Estes projetos demonstraram assuntos muito diferentes das aulas habituais que realizei. Foram importantes para conhecer melhor alguns assuntos relacionados à área farmacêutica". (Estudante 6).

\section{Discussão}

Ao analisarmos os resultados desta investigação, observamos que alguns dados são de interessante discussão. Um deles envolve o perfil destes estudantes, em sua maioria de mulheres que trabalham e estudaram em escolas públicas, no ensino médio.

Considera-se, com isto, que o comportamento das instituições de ensino superior para este público deva ser de acolhimento e estar disponível para amenizar as necessidades destes estudantes, muitas vezes com ensino defasado e sem tempo disponível para continuar se aprimorando no ensino superior.

Mesmo tendo muito contato com um tipo de ensino ainda enraizado na centralidade do professor e na proposta de estar passivamente adquirindo conhecimento, observou-se 
que a maioria dos estudantes percebeu a necessidade de ser motivada a refletir sobre os assuntos que the são propostos e não simplesmente memorizar informações.

Fica explicito que também a imaginação dos professores tutores deva ser estimulada, para produzir atividades e experiências instigantes e que motivem os estudantes a atuarem.

Neste contexto, Silva et al. (2011) também citam esta mesma condição em cenários de prática para estudantes de Farmácia, onde, neste ambiente, eles são motivados a refletir sobre as possíveis causas da existência do problema em estudo e tentar sua solução.

Por outro lado, a ideia de adquirir este conhecimento somente utilizando metodologias ativas é fortemente desaconselhada por estes estudantes, que acreditam que os conteúdos possam ser trabalhados associando as metodologias ativas com outros tipos de metodologias de ensino, até mesmo as tradicionais aulas expositivas, para embasamento de alguns conceitos importantes.

Em teoria, esta percepção pode vir do fato de que o aprendizado, por meio das metodologias ativas, é mais trabalhoso para ser atingido, em comparação com o comportamento passivo, quando se utiliza metodologias tradicionais. Surge a ideia do menor esforço, como algo a ser escolhido numa situação optativa. Porém, também deve fomentar o raciocínio do estudante, a angústia que se instaura durante as extensas aulas expositivas tradicionais. Por isto, a opção de escolherem uma situação intermediária, associando várias metodologias de ensino, seria menos estressante para eles.

O fato de ser uma técnica de ensino mais trabalhosa para os estudantes também foi debatido por Cecy et al. (2010), pois a metodologia ativa é uma estratégia centrada no estudante. Esse fato gera uma necessidade de mais estudo e isto exige mais horas de dedicação.

No entanto, há parte dos estudantes pesquisados que acham mais adequado entrar em contato com o tema a ser estudado do modo tradicional, através de aulas puramente expositivas.

Para estes, um problema sério que é instaurado quando estão matriculados em disciplinas que empregam metodologias ativas, principalmente nas instituições particulares, é a queixa em relação aos professores que "se negam a dar aulas expositivas", mesmo quando estes estudantes são avisados anteriormente, de como serão desenvolvidas as atividades.

Para eles, o acolhimento e discussão a respeito dos benefícios das metodologias ativas de ensino aprendizagem seria um dos caminhos para sanar estes conflitos. Morais 
(2014) também cita o mesmo problema observado na proposta de introduzir metodologias ativas para disciplinas do curso de Farmácia, também mencionando a mesma solução para estes conflitos.

Mesmo desta forma, grande maioria dos estudantes acharam que o uso de metodologias ativas facilitou seu entendimento e aprendizado sobre os assuntos tratados nas disciplinas Projetos Farmacêuticos e que foram necessários conhecimentos de outras disciplinas para desenvolver os projetos.

Ficou claro, observando as respostas dos estudantes (vide tabela 1 e as citações), que este trabalho não seria possível sem as tecnologias de informação e comunicação (TICs), principalmente relacionadas com uso das ferramentas de busca disponíveis na internet, como por exemplo, a busca por artigos científicos, fato que não é usual para eles, na sua relação de uso com a internet.

Isto deixou evidente para os estudantes que estas disciplinas têm a característica de serem interdisciplinares e transversais nos conteúdos e, desta forma, podem ir se familiarizando com este modo completo de pesquisa e raciocínio sobre um tema.

Algo assemelhado a estes resultados também foi observado por Limberger (2013), que relata a implantação de metodologias ativas de ensino aprendizagem em disciplinas do curso de Farmácia. Neste caso, foi observado nos estudantes o desenvolvimento de uma maior compreensão sobre o tema, maior retenção de conhecimentos, o despertar para a importância da interdisciplinaridade, sempre tendo, por foco, a resolução de um problema do paciente.

Também, a maioria dos estudantes assinalou que os projetos desenvolvidos, ou seja, o trabalho por eles executado, foi de importância para coletividade científica ou leiga. Eles perceberam, por meio da execução dos projetos, a importância de seu trabalho em contato com a coletividade acadêmica, ou fora dela.

Este reconhecimento do próprio estudante dignifica seu trabalho e estimula sua autoestima e seu papel como futuro profissional na sociedade.

Mesmo assim, a maioria dos estudantes optou por assinalar que estas disciplinas teriam uma importância mediana em sua formação profissional. Minoria optou por nenhuma importância ou grande importância.

Por outro lado, ao ler os comentários sobre esta questão (vide as citações), observou-se que o espírito científico, que envolve o profissional farmacêutico, foi despertado na maior parte deles, mostrando que atividades como aquelas desenvolvidas nestas disciplinas são ótimos exemplos para os estudantes, de como desempenhar 
integralmente sua vida profissional.

No mesmo sentido, em estudo realizado com egressos do curso de Farmácia, que tiveram sua matriz curricular baseada em metodologias ativas, Silva et al. (2019) avaliaram que, em torno de $70 \%$ dos egressos pesquisados admitem que as metodologias ativas facilitaram seu desenvolvimento crítico e sua atuação como farmacêutico.

Por fim, a avaliação realizada sobre as três disciplinas de Projetos Farmacêuticos que contextualizava a sua proposta, o desenvolvimento, os critérios de avaliação e a atuação do professor tutor, tiveram resultados aprovadores.

Resultados acima de $50 \%$ para a alternativa "interessante" para proposta, desenvolvimento e critérios de avaliação foram obtidos. Valor superior a $90 \%$ para a atuação dos professores tutores, se somarmos as porcentagens das respostas "bom" e "ótimo", foi atingido.

Covizzi e Andrade (2012) relatam em seu trabalho que avaliou a percepção dos estudantes com a introdução de metodologias ativas numa disciplina do curso de Farmácia, que houve maior proximidade entre estudante e professor tutor, de tal forma que, as relações criadas durante o desenvolvimento dos trabalhos na disciplina, fizeram com que as avaliações fossem maiores, neste quesito.

\section{CONCLUSÃO}

Considerando as limitações deste tipo de estudo que envolveu baixo número de estudantes, os resultados obtidos nesta pesquisa com discentes que passaram pelas disciplinas de Projetos Farmacêuticos, desenvolvidas utilizando a associação de metodologias ativas (Aprendizagem Baseada em Projetos) e tecnologias de informação e comunicação (TICs), observamos que, na percepção dos estudantes, elas facilitaram o entendimento sobre o assunto abordado, no sentido do estreitamento entre conhecimentos teóricos e práticos.

Por conta disto, sugere-se que avanços tenham ocorrido no desempenho dos estudantes, no que tange às suas habilidades, competências e atitudes para sua futura atuação profissional.

Os estudantes apreciaram como as disciplinas foram propostas, o desenvolvimento de conteúdos, o processo de avaliação e o desempenho do professor tutor.

Também foi percebido por eles, o resultado de seu trabalho na comunidade e a potencialidade desta metodologia de ensino aprendizagem em desenvolver no estudante 
qualidades, como o espírito investigativo.

No entanto, há ressalvas, por parte dos estudantes, para utilização de metodologias ativas de forma abrangente nas disciplinas. Observou-se nas respostas um viés para manutenção de parte do conteúdo sendo oferecido com outras metodologias de ensino, até mesmo usando as tradicionais aulas expositivas.

Sendo assim, de maneira geral, observou-se boa aceitação pelos estudantes para este tipo disciplina. No entanto, foi considerado negativo pelos discentes, o uso único e extensivo de metodologias ativas para sua formação profissional.

\section{REFERÊNCIAS}

ALVES, Josinete Salvador; MARUNO, Monica; BORELLA, Júlio Cézar. Projetos farmacêuticos: experiência de aprendizagem usando recursos tecnológicos de informação e comunicação. Revista Tecnologia Educacional, Rio de Janeiro, n.224, p. 114-124, 2019. Disponível em: http://abt-br.org.br/wp-content/uploads/2020/05/RTE-224.pdf. Acesso em: 7 jun. 2020.

BRASIL. Ministério da Saúde/Conselho Nacional de Saúde. Resolução n. 466, de 12 de dezembro de 2012. Aprova as diretrizes e normas regulamentadoras de pesquisas envolvendo seres humanos. Diário Oficial da República Federativa do Brasil, Brasília, DF, 13 jun. 2013. Seção I, p. 59.

BRASIL. Ministério da Educação/Instituto Nacional de Estudos e Pesquisas Educacionais Anísio Teixeira. Portaria $\mathbf{n}^{\circ}$. 291, de 8 de junho de 2016. Trata do Exame Nacional de Desempenho dos Estudantes. Diário Oficial da República Federativa do Brasil, Brasília, DF, 9 jun. 2016. Seção I, p. 11.

BRASIL. Ministério da Educação/Conselho Nacional de Educação. Resolução n. 6, de 19 de outubro de 2017. Institui as Diretrizes Curriculares Nacionais do Curso de Graduação em Farmácia. Diário Oficial da República Federativa do Brasil, Brasília, DF, 20 out. 2017. Seção I, p. 30-32.

CASTRO, Ana Flávia Luca. et al. A universidade brasileira: da colonização aos dias atuais. 
Serviço Social \& Realidade, v. 24, n. 2, p. 117-190. 2019. Disponível em: https://ojs.franca.unesp.br/index.php/SSR/article/download/2503/2209. Acesso em: 7 jun. 2020.

CECY, Carlos; OLIVEIRA, Geraldo Antônio; COSTA, Eula Maria Melo Barcelos Metodologias ativas: aplicações e vivências em educação farmacêutica. Brasília: Editora do CFF, 2010.

CHAGAS, Marina Oliveira. et al. Diretrizes curriculares nacionais do curso de farmácia: análise qualitativa comparativa 2002-2017. In: CONGRESSO IBERO-AMERICANO EM INVESTIGAÇÃO QUALITATIVA (8․). 2019, Lisboa. Atas de Investigação Qualitativa na Educação. v.1, 1011-1016. 2019. Disponível em: https://proceedings.ciaiq.org/index.php/ CIAIQ2019/article/view/2390. Acesso em: 7 jun. 2020.

CINTRA, Luciano Mendes. A relação entre o progresso tecnológico e o desemprego no Brasil nos anos de 2000 a 2015. Revista Eletrônica de Debates em Economia, v. 7, n. 1, 2019. Disponível em: http://periodicos.unifacef.com.br/index.php/rede/article/view/1713. Acesso em: 7 jun. 2020.

COVIZZI, Uderlei; ANDRADE, Patrícia Lopes. Estratégia para o ensino do metabolismo dos carboidratos para o curso de farmácia, utilizando metodologia ativa de ensino. Revista de Ensino de Bioquímica, v. 10, n. 1, p. 10-22, 2012. Disponível em: http://bioquimica.org.br/revista/ojs/index.php/REB/article/view/169/15. Acesso em: 7 jun. 2020.

DRIESSNACK, Martha; SOUSA, Valmi D.; MENDES, Isabel Amélia Costa. Revisão dos desenhos de pesquisa relevantes para enfermagem. Parte 1: desenhos de pesquisa quantitativa. Revista Latino-americana de Enfermagem v.15, n. 3, p. 502-507, 2007. Disponível em: https://www.redalyc.org/pdf/2814/281421877025.pdf. Acesso em: 7 jun.2020.

FARIAS, Pablo Antônio Mário; MARTIN, Ana Luiza Aguiar Rocha; CRISTO, Cinthia Sampaio. Aprendizagem ativa na educação em saúde: percurso histórico e 
aplicações. Revista brasileira de educação médica, v. 39, n. 1, p. 143-150, 2015. Disponível em: http://www.scielo.br/scielo.php?pid=S0100-55022015000100143\&script= sci_arttext\&tlng=es. Acesso em: 7 jun. 2020.

FONTELLES, Mauro José. et al. Metodologia da pesquisa científica: diretrizes para a elaboração de um protocolo de pesquisa. Revista Paraense de Medicina, v.23, n.3, p.1-8. 2009. Disponível em: http://files.bvs.br/upload/S/0101-5907/2009/v23n3/a1967.pdf. Acesso em: 7 jun. 2020.

LIMBERGER, Jane Beatriz. Metodologias ativas de ensino-aprendizagem para educação farmacêutica: um relato de experiência. Interface-Comunicação, Saúde, Educação, v.17, n.47, p. 969-975. 2013. Disponível em: https://www.scielosp.org/scielo.php?pid=S1414$32832013000400020 \&$ script=sci_arttext\&tlng=pt. Acesso em: 7 jun. 2020.

MORAIS, Danyelle Cristine Marini. Avaliação da experiência de estudantes de farmácia no componente curricular de farmacologia com a utilização da metodologia de aprendizagem baseada em tarefas. FOCO: caderno de estudos e pesquisas, v. 5, p. 89-109, 2014. Disponível em: http://www.revistafoco.inf.br/index.php/FocoFimi/article/view/34. Acesso em: 7 jun. 2020.

MINAYO, Maria Cecília Souza. Pesquisa Social, método e criatividade, 22 ed. Rio de Janeiro: Vozes, 2003.

NASCIMENTO, Marilene Cabral. et al. Formação em práticas integrativas e complementares em saúde: desafios para as universidades públicas. Trabalho, Educação e Saúde, v. 16, n. 2, p. 751-772, 2018. Disponível em: http://www.scielo.br/scielo.php?Script= sci_arttext\&pid=S1981-77462018000200751\&lng=pt\&nrm=iso\&tlng=pt. Acesso em: 7 jun. 2020.

POLIT, Denise F.; HUNGLER, Bernardette P. Fundamentos de Pesquisa em Enfermagem. 3 ed. Porto Alegre: Artes Médicas, 1995.

SILVA, Rinaldo Henrique Aguilar; MIGUEL, Soraida, Sozzi; TEIXEIRA, Luciana Scapin. Problematização como método ativo de ensino-aprendizagem: estudantes de farmácia em 
cenários de prática. Trabalho, Educação e Saúde, v. 9, n. 1, p.77-93. 2011. Disponível em: https://www.redalyc.org/pdf/4067/406757001003.pdf. Acesso em: 7 jun. 2020

SILVA, Elice Maria. et al. Perfil dos egressos de Farmácia de uma Faculdade de Saúde. Infarma, v. 31, n. 3, p. 259-270. 2019. Disponível em: http://revistas.cff.org.br/?journal= infarma\&page=article\&op=view\&path\%5B\%5D=2519. Acesso em: 7 jun. 2020.

SOUSA, lane Franceschet; BASTOS, Paulo Roberto Haidamus Oliveira Interdisciplinaridade e formação na área de farmácia. Trabalho, Educação e Saúde, v. 14, n. 1, p. 97-117, 2016. Disponível em: http://www.scielo.br/scielo.php?pid=S198177462016000100097\&script=sci_abstract\&tIng=es. Acesso em: 7 jun. 2020.

VENDRUSCOLO, Carine. et al. A informática na formação e qualificação dos profissionais de saúde: uma revisão integrativa. Revista de Enfermagem da UFSM, v.3, n.3, p. 539546. 2013. Disponível em: http://dx.doi.org/10.5902/217976927465. Acesso em: 7 jun. 2020.

Autor para correspondência:

Júlio Cézar BORELLA

Email: julio.borella@baraodemaua.br

Centro Universitário Barão de Mauá, Ribeirão Preto - SP.

Recebido: 11/04/2021 Aceite: 10/06/2021 